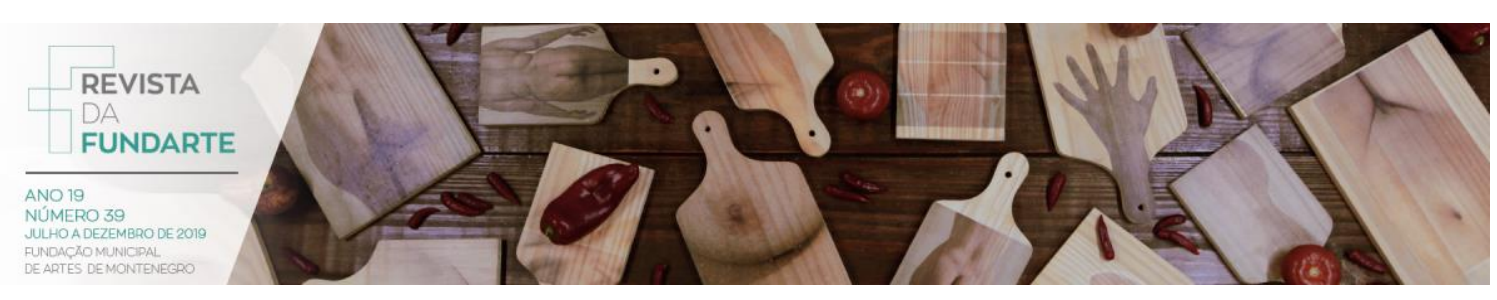

\title{
OLHARES SOBRE O TEATRO PARA CRIANÇAS, AS INFÂNCIAS E AS ESCOLAS
}

Diego de Medeiros Pereira Elisabete de Paula de Lemos Neris

PEREIRA, Diego de Medeiros; NERIS, Elisabete de Paula de Lemos. Olhares sobre o teatro para crianças, as infâncias e as escolas. Revista da FUNDARTE, Montenegro, p. 105-123, ano 19, nํ 39, julho/dezembro de 2019.

Disponível em: http://.seer.fundarte.rs.gov.br/index.php/RevistadaFundarte/index> 20 de dezembro de 2019. 


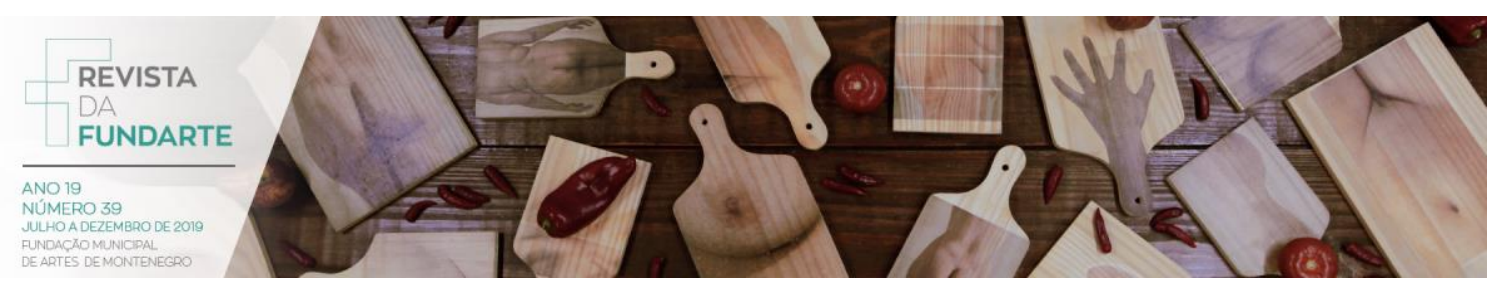

\title{
OLHARES SOBRE O TEATRO PARA CRIANÇAS, AS INFÂNCIAS E AS ESCOLAS
}

Diego de Medeiros Pereira ${ }^{1}$

Elisabete de Paula de Lemos Neris²

\begin{abstract}
Resumo: Este texto apresenta os resultados de dois anos de pesquisa teórico-prática acerca das relações entre teatro e diferentes infâncias. Por meio da exposição de levantamento bibliográfico realizado sobre o tema são discutidos os modos pelos quais se tem produzido espetáculos teatrais para crianças. A escola é enfatizada como um espaço de formação das referências artistas e estéticas de seus educandos. Reflexões acerca do processo de criação coletiva de um experimento cênico, bem como sua circulação por escolas da rede pública de ensino de Santa Maria (RS), põem em pauta a necessidade de que o teatro infantil seja objeto de estudo nos cursos de formação de professores e artistas de teatro.
\end{abstract}

Palavras-chave: Teatro para Crianças; Teatro e Escola; Infâncias.

\section{PERSPECTIVES ON THE THEATER FOR CHILDREN, CHILDHOOD AND SCHOOLS}

\begin{abstract}
The given text presents the results of two years of theoretical and practical research regarding the relations between Theater and different childhoods. Through the exposition of bibliographical surveys about this matter, we discuss the ways through wich theatrical plays for children are produced. School is enphasized as a place of formation of artistic and esthetic referrences of it's students. Refletions about the colective creational process of a scenic experiment, as well as it's circulation through schools of the public system of education of Santa Maria (RS), highlight the necessity of children's theater becoming a matter of study in theacher training and theater artists classes.
\end{abstract}

Keywords: Theater for children; Theater and School; Childhoods.

- Quinhentos milhões de quê?

- Também não. Essas coisinhas douradas que fazem sonhar os ociosos. Eu cá sou um sujeito sério. Não tenho tempo para divagações.

- Ah! Estrelas?

- Isso mesmo. Estrelas.

- E que fazes tu de quinhentos milhões de estrelas? - Quinhentos e um milhões, seiscentos e vinte e duas mil, setecentos e trinta e uma. Eu sou um sujeito sério. Gosto de exatidão. [...]

(Saint-Exupéry em O Pequeno Príncipe ,1989)

\footnotetext{
1 Doutor em Teatro. Professor no Departamento de Artes Cênicas da Universidade do Estado de Santa Catarina (UDESC), líder do Grupo de Estudos sobre Teatro e Infâncias (GETIs/CNPq). Área: Pedagogia do Teatro.

${ }^{2}$ Graduanda em Licenciatura em Teatro. Bolsista do Fundo de Incentivo à Pesquisa (FIPE/UFSM). Membra do Grupo de Estudos sobre Teatro e Infâncias (GETIs/CNPq).
}

PEREIRA, Diego de Medeiros; NERIS, Elisabete de Paula de Lemos. Olhares sobre o teatro para crianças, as infâncias e as escolas. Revista da FUNDARTE, Montenegro, p. 105-123, ano 19, nํ 39, julho/dezembro de 2019.

Disponível em: http://.seer.fundarte.rs.gov.br/index.php/RevistadaFundarte/index> 20 de dezembro de 2019. 


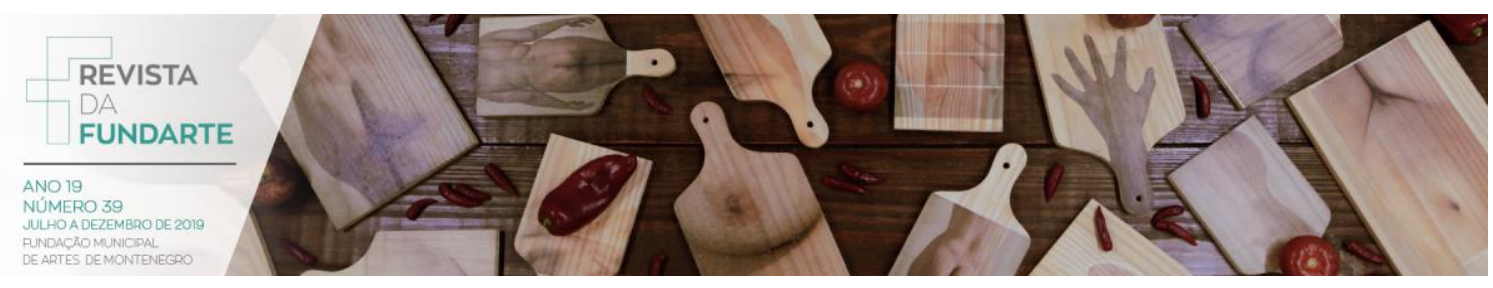

\section{Introdução}

O presente artigo estabelece algumas reflexões sobre as atividades de pesquisa teórica e criação cênica compreendidas pelo projeto "Teatro e infâncias: investigações acerca de práticas teatrais desenvolvidas com crianças", que deu origem ao Grupo de Estudos sobre Teatro e Infâncias - GETIs/CNPq, formado no ano de 2017 por estudantes de Licenciatura em Teatro e Bacharelado em Artes Cênicas, da Universidade Federal de Santa Maria - UFSM.

Paralelo à abordagem referente às ações realizadas ao longo dos dois anos do projeto, que contribuíram diretamente na produção de um experimento cênico intitulado "Atenção para a Chamada!", compartilhado em espaços públicos da Educação Básica do município, este artigo intenciona, também, fomentar reflexões acerca das criações teatrais direcionadas ao público infantil.

Diante de um cenário de produções cênicas voltadas às crianças bastante heterogêneo, mas que, de maneira geral, ainda trata de modo superficial (em forma e conteúdo) as especificidades das diferentes infâncias contemporâneas, o GETIs foi instigado a se aproximar de trabalhos artísticos, referenciais teóricos e práticas artístico-pedagógicas com foco na linguagem teatral que questionassem a maneira tradicional de ver/pensar/fazer teatro para crianças.

O Grupo de Estudos possuía, inicialmente, dois principais focos de ação: a realização de encontros destinados à leitura de materiais teóricos que abordassem relações entre teatro e infâncias, a partir da pesquisa bibliográfica realizada pela bolsista $^{3}$, e encontros "práticos" com o objetivo de desenvolver um experimento cênico, a ser compartilhado em espaços de educação do município que incentivasse as crianças espectadoras a se envolverem afetivamente com a cena e que convocasse sua ludicidade ao "experimentar" o espetáculo, características essas frequentemente negligenciadas nas produções voltadas a esse público, muitas delas com caráter didático e moralizante.

\footnotetext{
${ }^{3}$ Projeto de Pesquisa contemplado nos anos de 2017 e 2018 com uma bolsa de iniciação científica do Fundo de Incentivo à Pesquisa - FIPE/CAL/UFSM.

PEREIRA, Diego de Medeiros; NERIS, Elisabete de Paula de Lemos. Olhares sobre o teatro para crianças, as infâncias e as escolas. Revista da FUNDARTE, Montenegro, p. 105-123, ano 19, no 39, julho/dezembro de 2019.

Disponível em: http://.seer.fundarte.rs.gov.br/index.php/RevistadaFundarte/index> 20 de dezembro de 2019.
} 


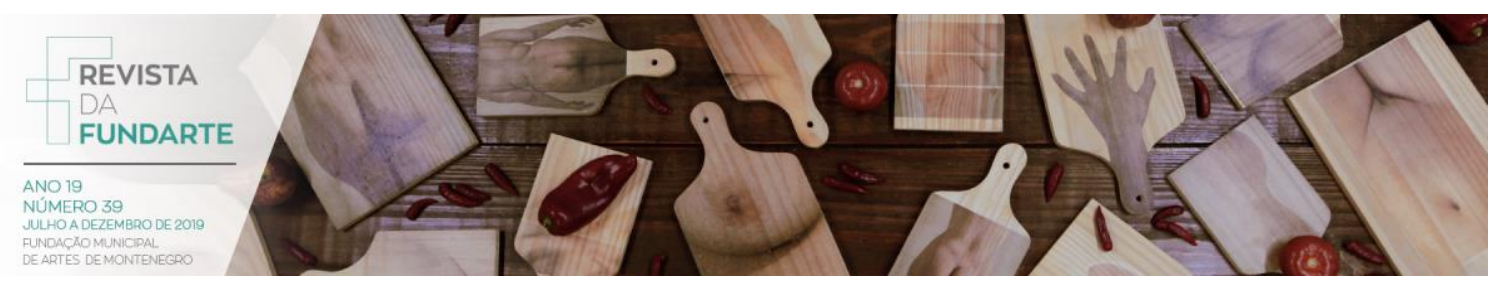

Destacamos, a seguir, o processo de levantamento bibliográfico sobre o tema "Teatro e Infâncias", bem como as principais reflexões geradas a partir da leitura de parte desses materiais. Na sequência, apontaremos os referenciais teóricos discutidos no GETIs e a maneira como eles influenciaram a criação do espetáculo "Atenção para a Chamada!", o qual será pontuado ao final deste texto, estabelecendo paralelos com as principais discussões contemporâneas sobre o teatro para crianças e sua relação com a instituição escola.

\section{O Teatro e as Infâncias}

A partir de inquietações sobre os modos como se tem produzido teatro para crianças e o quanto essas práticas artísticas e a consequente discussão sobre elas se encontra distante das formações acadêmicas em Teatro - seja nos cursos de Licenciatura ou de Bacharelado - um grupo de artistas/estudantes/futuros docentes se reuniu para a criação de um grupo de pesquisa teórico-prático. Desenvolver um minucioso levantamento bibliográfico, seguido de leituras dos materiais encontrados e, paralelamente, desenvolver laboratórios de experimentação e criação cênicas com vistas à elaboração de um material passível de compartilhamento com o público infantil, passaram a ser os objetivos do grupo.

O levantamento inicial propunha analisar revistas de pós-graduação nas áreas de Teatro e Artes Cênicas, na procura por textos produzidos nos últimos 15 anos, que estabelecessem reflexões sobre os seguintes temas: teatro e infâncias, teatro infantil e teatro para crianças; além de outras fontes de materiais que fossem encontradas ao longo do levantamento de material bibliográfico.

Ao todo foram encontradas 17 revistas e dessas, foram retirados 30 artigos, os quais foram lidos e analisados semanalmente, por bolsista e coordenador do projeto, no intuito de classificá-los de acordo com o conteúdo que abordavam.

Outros locais de grande contribuição para a pesquisa, que apresentam textos escritos por acadêmicos e por estudiosos e artistas do Teatro para Crianças e Jovens, foram os sites do Centro Brasileiro de Teatro para a Infância e Juventude

PEREIRA, Diego de Medeiros; NERIS, Elisabete de Paula de Lemos. Olhares sobre o teatro para crianças, as infâncias e as escolas. Revista da FUNDARTE, Montenegro, p. 105-123, ano 19, no 39 , julho/dezembro de 2019.

Disponível em: http://.seer.fundarte.rs.gov.br/index.php/RevistadaFundarte/index $>20$ de dezembro de 2019. 


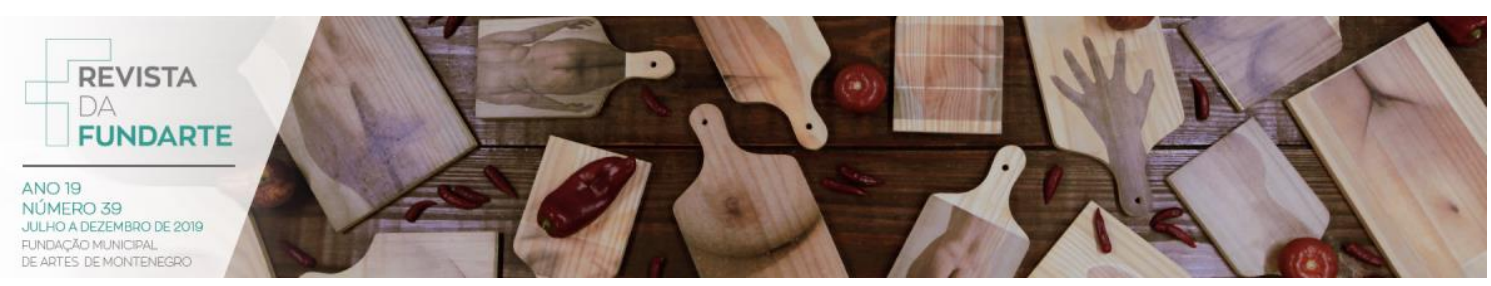

(CBTIJ), do qual foram retirados 41 textos, e do Centro de Pesquisa e Estudos do Teatro Infantil (CEPETIN), por meio do qual tivemos acesso a 43 artigos atualmente em processo de leitura por bolsista e coordenador. Destacamos, também, os diversos números da Revista do FENATIB - Festival Nacional de Teatro para Crianças de Jovens de Blumenau (SC), que tivemos acesso e estamos em processo de análise, e a recente Panacea - Revista de Estudos sobre Teatro para Crianças e Jovens, lançada em 2018.

Para um melhor dimensionamento das discussões propostas, distribuímos os materiais selecionados nas seguintes classificações por nós elaboradas:

A - Discussões sobre a Infância;

B - Teatro para Crianças;

C - Criança Contemporânea;

D - Discussões gerais sobre Teatro;

E - Teatro como Ferramenta e

F - Relações entre Teatro e Escola.

Diversos materiais selecionados discutiam as infâncias a partir de sua contextualização histórica, aparecendo como principal expoente a obra "História Social da Infância e da Família" (1978), de Philippe Ariès. Outra perspectiva bastante presente nos materiais foi o olhar sobre o desenvolvimento infantil pela perspectiva da Psicologia, principalmente se relacionando com as obras de Jean Piaget (1896-1980). Alguns textos mais recentes, ao tratarem das infâncias - no plural e reconhecendo sua pluralidade - pautam-se nos escritos de Manuel Sarmento, professor e estudioso português que inaugurou o campo da Sociologia da Infância.

Entre os materiais que se direcionavam a pensar as relações entre o teatro e as crianças, os conteúdos mais presentes eram discussões sobre dramaturgia infantil e conteúdos abordados pelos espetáculos, em geral, discutindo/questionando a perspectiva didática dessas obras. O livro "No Reino da Desigualdade" (1991), de Maria Lúcia de Souza Pupo, foi apontado como principal referência nesses escritos.

PEREIRA, Diego de Medeiros; NERIS, Elisabete de Paula de Lemos. Olhares sobre o teatro para crianças, as infâncias e as escolas. Revista da FUNDARTE, Montenegro, p. 105-123, ano 19, no 39, julho/dezembro de 2019.

Disponível em: http://.seer.fundarte.rs.gov.br/index.php/RevistadaFundarte/index> 20 de dezembro de 2019. 


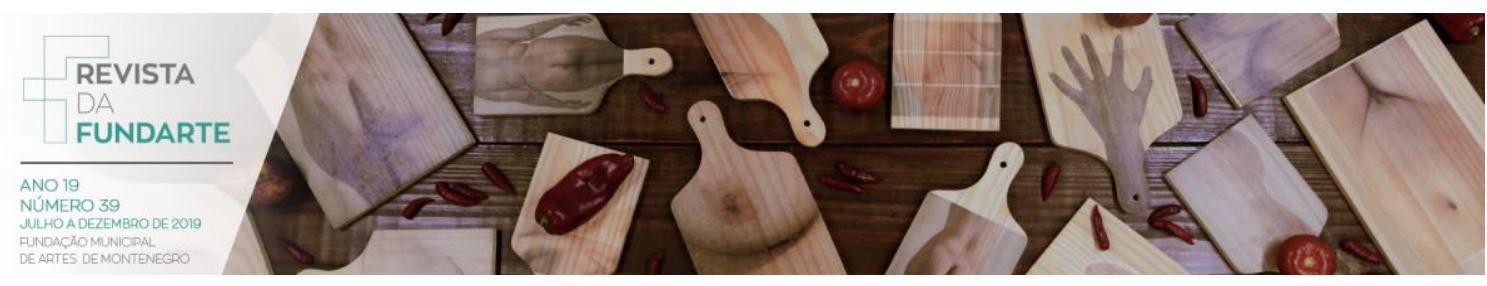

Destacamos que uma visão tradicional que relaciona o teatro infantil com fins didáticos ainda é fortemente acentuada nos materiais lidos, com ressalva para artigos como: "Dramaturgia no teatro para a infância e a juventude" (2005), de Marco Camarotti, "O que precisamos saber ou lembrar sobre a criança e sobre o teatro" (2006), de Maria Helena Kuhner, que se apoiam em argumentos mais artísticos e menos didáticos e "Em busca de uma semântica do Teatro Infantil" (2014), de Luvel Garcia Leyva, que apresenta diferentes perspectivas sobre o teatro infantil na cena contemporânea. Outro tema encontrado nesses materiais, porém que apareceu em poucas discussões, foi o trabalho do ator pensado para o público infantil, que fuja de representações estereotipadas de crianças.

Novas estruturas e elementos presentes na formação das infâncias contemporâneas apareceram como temas relacionados, por exemplo, à produção massiva da indústria cultural voltada à infância, difundida por intermédio dos meios audiovisuais. Destacamos o livro "Reflexões sobre a criança, o brinquedo e a educação" (2009) ${ }^{4}$, de Walter Benjamin, o qual apresenta uma perspectiva crítica sobre os processos formativos experimentados pela criança ao longo de sua constituição como sujeito e da influência dos objetos estéticos nessa formação.

Por fim, o último tema elencado tratou sobre teatro na escola a partir de diversos prismas: encenações teatrais utilizadas como ferramenta para o ensino de outros componentes curriculares, o espaço escolar como uma rota de mercado para a comercialização de peças infanto-juvenis e falta de apuramento estético e crítico nas produções direcionadas ao ambiente escolar. Apontamos os livros "Jogo, Teatro e Pensamento" (1974), de Richard Courtney e "Jogos Teatrais" (1984), de Ingrid Koudela, como bibliografias presentes que circularam esse tema.

Por meio de uma análise quantitativa e qualitativa dos materiais levantados, foi possível perceber o quanto as relações entre teatro e infâncias são pouco exploradas no meio acadêmico. Dimensionar essa produção teórica se fez fundamental para melhor definirmos o foco de estudo do GETIs.

\footnotetext{
${ }^{4}$ Original, em alemão, de 1969.
}

PEREIRA, Diego de Medeiros; NERIS, Elisabete de Paula de Lemos. Olhares sobre o teatro para crianças, as infâncias e as escolas. Revista da FUNDARTE, Montenegro, p. 105-123, ano 19, no 39 , julho/dezembro de 2019.

Disponível em: http://.seer.fundarte.rs.gov.br/index.php/RevistadaFundarte/index> 20 de dezembro de 2019. 


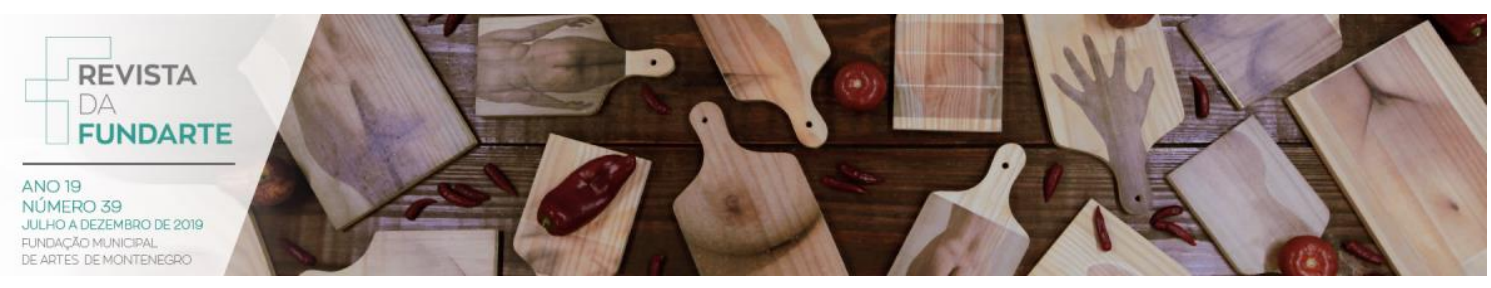

Levando-se em consideração que em meados do século $X X$ foram desenvolvidos estudos sociológicos específicos sobre a criança, tratando-a como ser social que produz cultura dentro de um grupo no qual está inserida, assim como foram reconhecidas as suas particularidades como sujeito ativo que compartilha tempos e espaços com os adultos, e que os cursos superiores em teatro no Brasil surgiram na década de 1970, podemos considerar que a quantidade de materiais teóricos encontrados sobre o tema, foi, no mínimo, inferior a outros temas de pesquisa na área do Teatro.

Nesse sentido, questionamos: o que leva o teatro infantil a ser tão pouco pesquisado quando comparado a outros gêneros teatrais? Estaria a imagem do teatro infantil ainda erroneamente atrelada à prática de "fazer qualquer coisa" por ser voltado à criança, visto que, em pleno século $\mathrm{XXI}$, predomina o senso comum de que crianças se agradam com pouco, dado seu olhar inexperiente e seu pouco repertório?

Indagamos se o teatro infantil não é discriminado perante os demais gêneros teatrais por direcionar seu trabalho à criança, até pouco tempo desconsiderado como um ser social. Para nós, as palavras de Pupo ainda parecem fazer sentido: "Na medida em que é encarada como atividade artística menor, a realização teatral dirigida à infância tende a eximir seus responsáveis de maiores cuidados ou inquietações de caráter estético" (1991, p. 39).

Nós insistimos na provocação: as crianças se agradam com pouco ou somos nós que pouco exploramos sua capacidade lúdica, de leitura de imagens, de decifração de códigos e símbolos, de abstração. Em diálogo com Kühner:

\footnotetext{
Os "adultos" que só fisicamente cresceram não conseguem entender que uma Menina possa montar na cacunda do vento e sair pelos ares; tem que buscar "explicações" para esse "rapto" falando em polícia, drogas, cartas em códigos, chefes de bando a serem presos, tudo que sua sensibilidade atrofiada os valores dogmáticos e convencionais das regras sociais estabelecem. Mas será tudo inútil, pois, como sabemos, não adianta querer prender o vento. (KÜHNER, 2006, p. 12-13).
}

PEREIRA, Diego de Medeiros; NERIS, Elisabete de Paula de Lemos. Olhares sobre o teatro para crianças, as infâncias e as escolas. Revista da FUNDARTE, Montenegro, p. 105-123, ano 19, n 39, julho/dezembro de 2019.

Disponível em: http://.seer.fundarte.rs.gov.br/index.php/RevistadaFundarte/index> 20 de dezembro de 2019. 


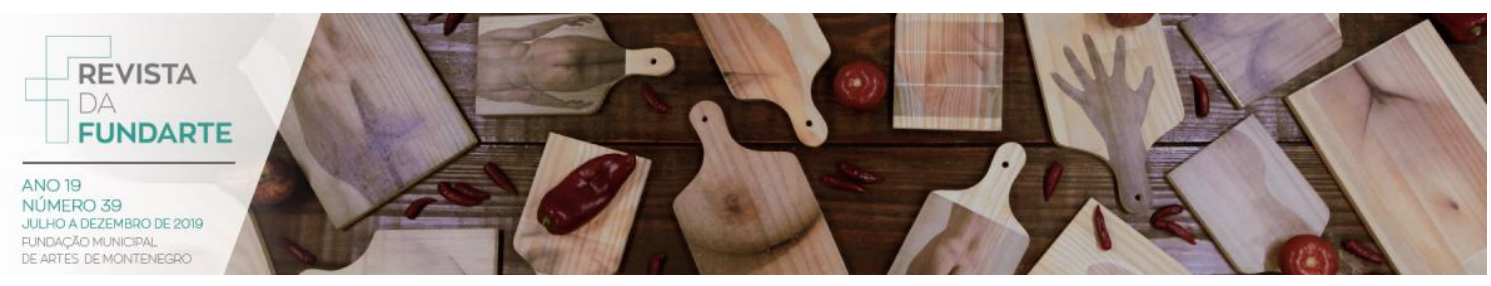

O repertório cultural das crianças sofre influência direta das nossas ofertas principalmente de seus pais e professores. Como possibilitar experiências de contato com o teatro no cotidiano? Gilka Girardello aponta que "[...] a experiência cotidiana das crianças, seu enraizamento sociocultural, faz uma enorme diferença na forma como cada criança recebe os produtos de arte e informação que nós, adultos, Ihes oferecemos [...]" (2005, p. 39).

A questão que fica é: não seremos nós "sujeitos sérios", como aponta SaintExupéry (1989), que possibilitamos poucas oportunidades para as crianças? Não seríamos nós, artistas, que consideramos que fazer teatro para crianças é uma arte menor que, supostamente, exige menos apuramento técnico e artístico? Como estudiosos, professores e artistas de teatro, não estaríamos negligenciando uma melhor formação estética e cultural das futuras gerações?

\section{Teatro para Crianças e a Escola}

Mediante pesquisa documental realizada pelo GETIs, percebemos que muitas produções voltadas ao público infantil exploram, de maneira reducionista, as capacidades de leitura/decodificação de diferentes tessituras cênicas por parte das crianças. Espetáculos que se aproveitam de uma suposta inocência e falta de repertório teatral expõem reproduções genéricas sobre o mundo, assim como reiteram estereótipos de modos de ser e estar da criança, frequentemente "infantilizando" atores em cena, desmerecendo os comportamentos da criança, assim como, afirmando demarcações de gênero, etnia, funções sociais, por meio da exposição de modelos questionáveis.

Observamos que o espaço escolar tem sido, ao longo dos anos, um grande nicho de mercado para produções infanto-juvenis pouco elaboradas em forma e conteúdo. Percebemos, também, que essas instituições, muitas vezes, não analisam as peças que recebem ou que levam as crianças para assistir, ou mesmo não possuem um discernimento crítico sobre as produções teatrais. Excessos de

PEREIRA, Diego de Medeiros; NERIS, Elisabete de Paula de Lemos. Olhares sobre o teatro para crianças, as infâncias e as escolas. Revista da FUNDARTE, Montenegro, p. 105-123, ano 19, no 39, julho/dezembro de 2019.

Disponível em: http://.seer.fundarte.rs.gov.br/index.php/RevistadaFundarte/index> 20 de dezembro de 2019. 


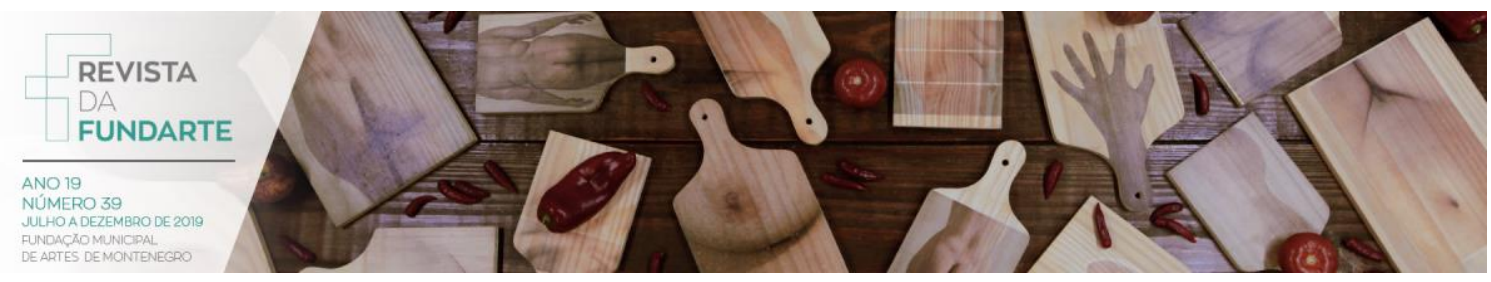

didatismo, acúmulo de imagens, sons e cores é o que se proporciona, frequentemente, ao público infantil escolar.

Dib Carneiro Neto no livro Pecinha É a Vovozinha! (2003), entre as páginas 10 e 19, destaca 10 tópicos sobre os equívocos mais predominantes quando se trata de apresentações de teatro para crianças. São eles:

Excesso de intenção didáticas;

Uso humor fácil e grosseiro;

Excesso de efeitos multimídia;

A obsessão pela lição de moral;

O lobo mau ficou bonzinho;

Participação forçada da plateia;

A camisa de força dos rótulos;

A síndrome do nariz de palhaço;

O desleixo nos diálogos e

As armadilhas da hora do sorteio.

À mercê de produções desse caráter, a escola, na ânsia por oferecer algo às crianças ou por falta de um repertório que lhe possibilite estabelecer melhores critérios artísticos e estéticos, abre suas portas à diferentes grupos. Onde se encontra a raiz dessas práticas? $\mathrm{Na}$ falta de um maior repertório teatral dos pais e professores? Na ausência de um conhecimento mais aprofundado sobre qual a função que o teatro pode desempenhar como linguagem artística e experiência estética no espaço escolar? Estaria o teatro sendo considerado apenas um período de descontração e relaxamento ou ainda inserido em uma visão tradicional que o compreende como ferramenta de educação? Para Pereira,

Há uma preocupação com os modos de se trabalhar o teatro com crianças, o que, em geral, se dá por meio da montagem de "pecinhas" sem uma clareza dos procedimentos pedagógicos que envolvem o fazer teatral, focando-se, quase que exclusivamente, na criação de um produto a serviço de temas escolhidos pelas escolas ou por um calendário de eventos, em geral religiosos ou cívicos. (PEREIRA, 2018, p. 103).

Consideramos importante que o teatro seja compreendido como uma forma artística estimulante e significativa para a criança, que a permita imergir em uma

PEREIRA, Diego de Medeiros; NERIS, Elisabete de Paula de Lemos. Olhares sobre o teatro para crianças, as infâncias e as escolas. Revista da FUNDARTE, Montenegro, p. 105-123, ano 19, nº 39, julho/dezembro de 2019.

Disponível em: http://.seer.fundarte.rs.gov.br/index.php/RevistadaFundarte/index> 20 de dezembro de 2019. 


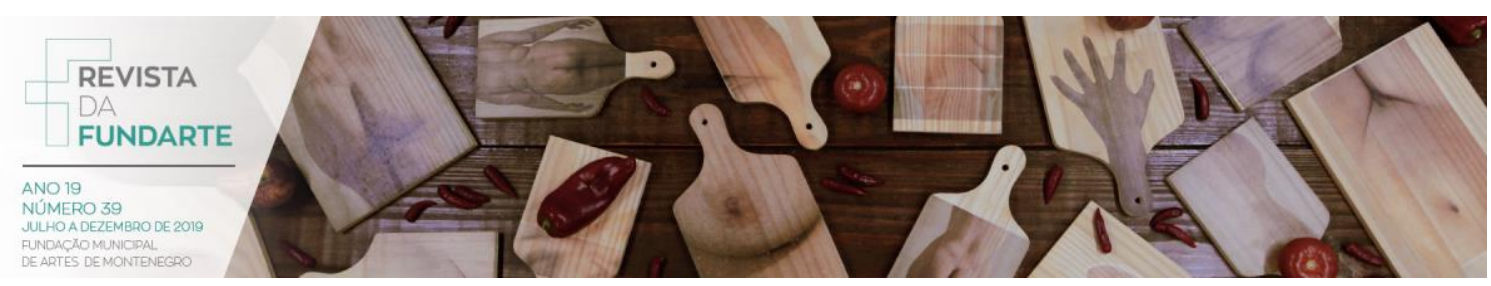

experiência estética, construindo sentidos a partir das percepções e sensações geradas pela fruição teatral. Como, entretanto, fazer o adulto compreender a importância desse espaço se, muitas vezes, ele não se permite estar em contato com essa arte e o que ela pode gerar? Como ampliar a percepção dos adultos sobre experiências que não possuem uma finalidade prática, mas que pertencem à esfera do sentir, do apreciar? Antoine Saint-Exupéry já afirmava que "o essencial é invisível aos olhos" (1989) ou como sugere Maria Helena Kühner:

Perceber: o visível que se percebe com os olhos, o sensível que se percebe pelos sentidos. Mas perceber não é ver ou sentir um amontoado de impressões que trairiam à elas (crianças) lembranças ou associações capazes de completá-las. É ver surgir, de uma constelação de dados, um sentido. Quando a criança começa a passear seu olhar inquieto e indagador pelo mundo dos objetos em torno, pelas pessoas e coisas que a cercam, é sua percepção que vai informar sua experiência de situar-se em meio a esses objetos e ter uma primeira resposta ao quem sou eu? [...]. (KÜHNER, 2006, p. 05).

As incompreensões sobre as potencialidades do teatro no ambiente escolar e a pouca importância a ele dedicada na formação dos sujeitos, parecem alicerçadas em pensamentos equivocados de que o teatro para crianças deve "transmitir" uma lição de moral, de que o bem deve vencer o mal predominando o final feliz e, se possível não tratar de temas como morte, perda, sexualidade ou solidão. Proporcionar uma peça autoexplicativa é o mais recorrente quando se produz um trabalho teatral voltado à escola ou quando se assiste a uma produção para esse público.

O modo como o teatro é (des)valorizado pela escola parece diretamente relacionado à sua presença nesse espaço. Sabe-se que muitas instituições não possuem um(a) professor(a) específico(a) dessa linguagem e, nesse sentido, reafirmamos que o ensino de teatro deveria ser atribuído a profissionais da área, que o compreendam como linguagem com características próprias e específicas. Será esse profissional um mediador entre os modos de produção e apreciação da linguagem teatral pelas crianças e um agente de promoção do teatro na e pela escola.

PEREIRA, Diego de Medeiros; NERIS, Elisabete de Paula de Lemos. Olhares sobre o teatro para crianças, as infâncias e as escolas. Revista da FUNDARTE, Montenegro, p. 105-123, ano 19, no 39, julho/dezembro de 2019.

Disponível em: http://.seer.fundarte.rs.gov.br/index.php/RevistadaFundarte/index> 20 de dezembro de 2019. 


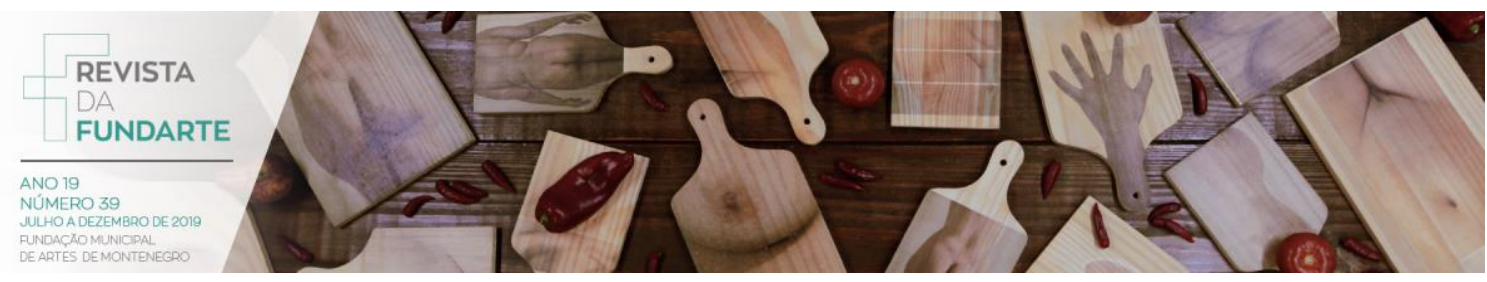

Sabemos que na realidade do ensino escolar brasileiro, ainda ocorre (não de forma isolada) que professores de outras áreas acabem incumbidos de ministrar as aulas de artes visuais, teatro, dança e/ou música. Não estamos questionando a boa vontade ou disposição desses professores, porém compreendemos que existe um repertório de práticas, vivências e teorias que a formação específica proporciona ao docente, tornando-o um profissional dessa área. Como defende Taís Ferreira:

Queremos nas escolas e nos espaços educacionais informais um docenteartista [...]. Queremos um docente-artista que dialogue com seus alunos e alunas, em um intercâmbio de desejos criativos e na promoção de sua execução/concretização ou um docente em arte que transmita verticalmente conhecimentos que possui na linguagem? (FERREIRA, 2008, p. 07).

Outro ponto relevante na presente discussão, e que permeia as inquietações do GETIs, é a ausência familiar na formação estética dos sujeitos sendo substituída pela indústria cultural voltada às infâncias. É inquestionável a mudança nas relações afetivas e no tempo/qualidade de contato entre pais e filhos na sociedade contemporânea. Em um contexto em que o trabalho é tido como o principal fator contribuinte para uma melhor "qualidade" de vida, tornou-se comum que os adultos trabalhem muito e, consequentemente, permaneçam afastados, por um longo período de tempo, do convívio com as crianças.

Duas palavras se alteraram com essa corrida em busca da suposta estabilidade financeira: o embalar, que outrora remetia ao movimento proveniente do filho no colo da mãe/pai, hoje alude ao objeto "embalado" que é entregue à criança em forma de presente, o qual busca suprir uma ausência, uma vez que os adultos raramente estão presentes (físico e mentalmente) para participarem e usufruírem dos momentos de brincadeira da criança com seu objeto ou mesmo para compartilharem uma ida ao teatro.

Algumas famílias - em geral as que dispõem de melhores condições financeiras - sob o prisma de que assistir a peças teatrais é uma atividade "culta", que thes confere um status diferenciado, favorecem o contato das crianças com produções dessa indústria. Tais produtos, entretanto, apresentam, em geral, forte

PEREIRA, Diego de Medeiros; NERIS, Elisabete de Paula de Lemos. Olhares sobre o teatro para crianças, as infâncias e as escolas. Revista da FUNDARTE, Montenegro, p. 105-123, ano 19, no 39, julho/dezembro de 2019.

Disponível em: http://.seer.fundarte.rs.gov.br/index.php/RevistadaFundarte/index> 20 de dezembro de 2019. 


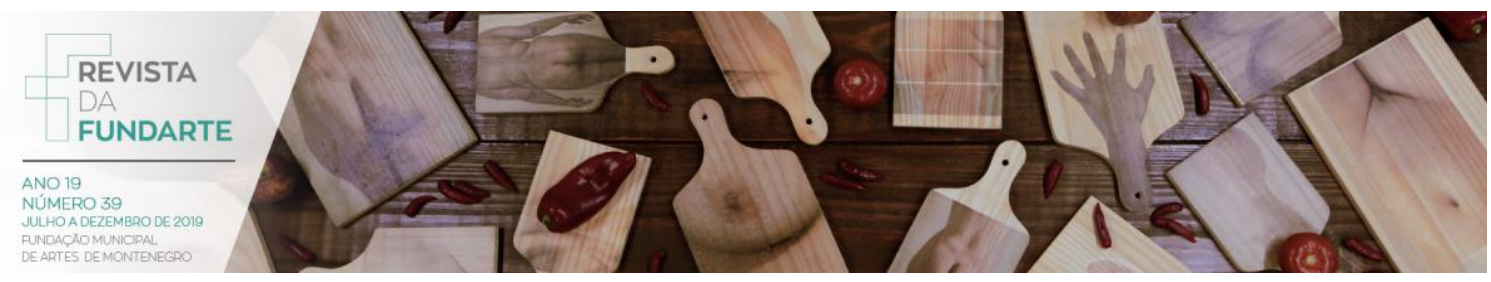

apelo comercial, muitos deles apelando para reproduções de filmes infantis no palco. As experiências proporcionadas por essas produções pouco atendem à uma formação estética de seus filhos ou ampliação do imaginário infantil. Esses trabalhos são conduzidos muito mais às anestesias que aos devaneios; a criança permanece presa ao senso comum familiar de apreciação cultural.

Foi no intuito de ampliar os repertórios artísticos e estéticos, tanto de crianças quanto de professores, assim como estabelecer diferentes olhares sobre as produções teatrais voltadas às infâncias, que o GETls propôs para si, como um dos seus focos de trabalho, a criação de um experimento cênico voltado aos públicos de diferentes idades, mas que levasse em consideração as especificidades da criança. O último tópico deste texto, portanto, será dedicado às reflexões geradas a partir da criação do espetáculo "Atenção para a Chamada!" e de sua circulação por instituições de ensino públicas da cidade de Santa Maria (RS).

\section{Atenção para a Chamada!: teatro contemporâneo para crianças}

Repletos de questionamentos, como todo início de processo criativo, percebemos que, embora não soubéssemos exatamente o que iríamos criar, uma vez que se tratava de um processo colaborativo, tínhamos certeza sobre o que não gostaríamos de reproduzir para o público infantil. Queríamos que o experimento dialogasse com a cena contemporânea, em que a fábula cede lugar aos discursos dos corpos dos performers, seus desejos, anseios, questionamentos, em diálogo com o que aponta Leyva:

[...] é precisamente a multiplicidade de identidades, práticas ou disciplinas teatrais, permeadas pelos processos diferenciais em seu interior, e a sua relação com as diversas culturas infantis e suas performances, as que conformam um tecido heterogêneo que demarca, à luz da contemporaneidade, o termo teatro infantil. [...] Enquanto modelização e espelho das culturas infantis, essas expressões teatrais colocam-se à disposição dos desejos e questionamentos dos pesquisadores. (LEYVA, 2014, p. 36-37).

PEREIRA, Diego de Medeiros; NERIS, Elisabete de Paula de Lemos. Olhares sobre o teatro para crianças, as infâncias e as escolas. Revista da FUNDARTE, Montenegro, p. 105-123, ano 19, nº 39, julho/dezembro de 2019.

Disponível em: http://.seer.fundarte.rs.gov.br/index.php/RevistadaFundarte/index> 20 de dezembro de 2019. 


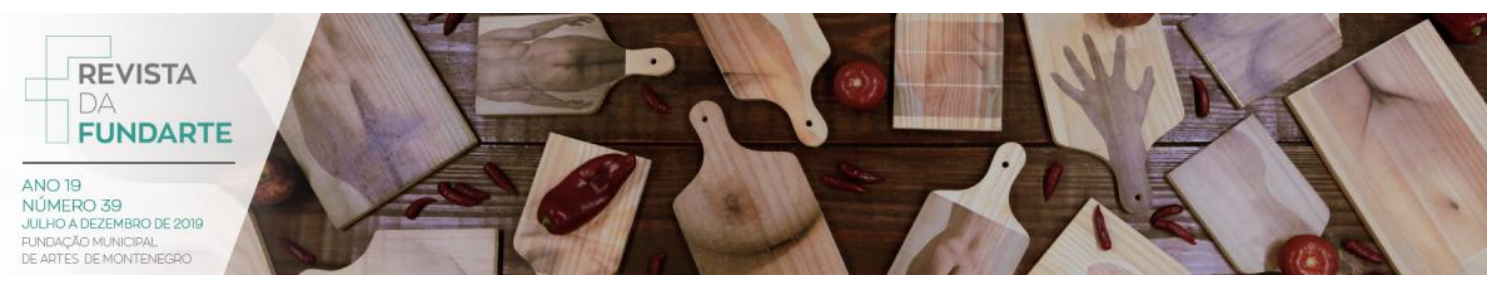

Tendo as discussões teóricas em mente e estabelecendo um diálogo com o livro "Cacos de Infância" (2004), de Marina Marcondes Machado, iniciamos, em maio de 2017, os laboratórios semanais de experimentação cênica que dariam origem ao espetáculo “Atenção para a Chamada!" que, naquele momento, já tinha um destino ser compartilhado em espaços públicos de educação básica do município e dialogar com o ambiente escolar.

A noção de agachamento, proposta por Machado, também ressoava em nosso processo criativo. "[...] são atitudes de agachamento: maneiras de estar perto da criança compartilhando a capacidade humana da imaginação comungada em maneiras de brincar" (2014, p. 08). A autora destaca que o agachamento não consiste em uma teoria, ele é, acima de tudo, uma conduta de ser e estar no mundo; uma atitude fenomenológica do adulto frente à criança. "[...] Agachar-se é ir ao chão, onde a criança está" (2014, p. 06).

Nesse contexto, nossa provocação era: como elaborar um produto cênico em que a criança experimentasse o trabalho, fosse uma parceira de jogo se sentindo convocada a assumir o protagonismo da cena, a brincar com os performers. Brincar... seria esse um bom começo.

Após um longo período de pesquisa e experimentação de materiais, mobilizados pelo anseio de produzir uma montagem teatral em que a criança não fosse um receptáculo de informações. O questionamento que se estabelecia era: o que queremos falar por meio do teatro para/com as crianças? Que história queremos contar? Queríamos, de fato, contar uma história ou abrir um espaço para que uma experiência fosse compartilhada?

Para a criação de "Atenção para a Chamada!", foi necessário reeducar nosso olhar frente à infância; praticar atitudes de agachamento nos momentos de pesquisa e criação foi de suma importância para que conseguíssemos evitar, ao máximo, direcionar nossa montagem à uma leitura fechada de mundo, à reprodução de estereótipos, à imitação da criança em cena, aos "truques" para "conquistar" as crianças com muitas cores, gritos, sustos, empurrões, cantoria, correria, etc.

PEREIRA, Diego de Medeiros; NERIS, Elisabete de Paula de Lemos. Olhares sobre o teatro para crianças, as infâncias e as escolas. Revista da FUNDARTE, Montenegro, p. 105-123, ano 19, nํ 39, julho/dezembro de 2019.

Disponível em: http://.seer.fundarte.rs.gov.br/index.php/RevistadaFundarte/index> 20 de dezembro de 2019. 


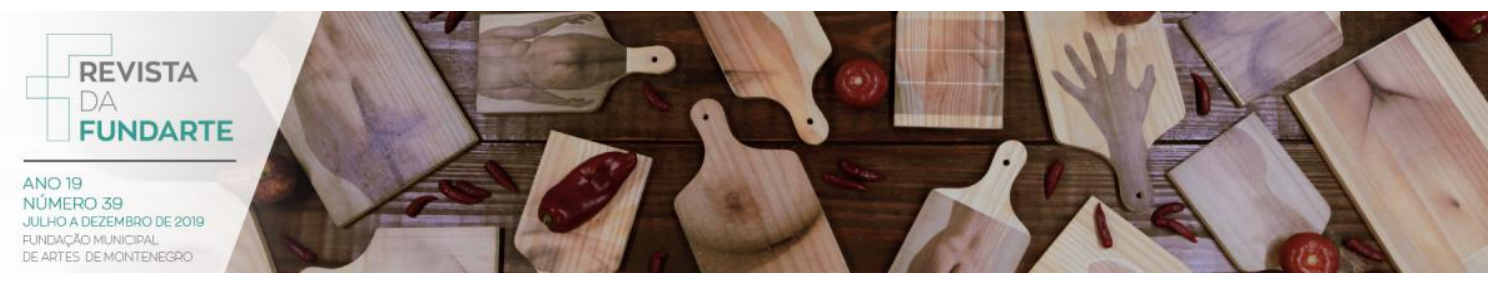

Outra definição, já explorada em estudos anteriores, mas que voltou a ser visitada por nós, foi o conceito de espaço potencial, proposto pelo pediatra e psicanalista Donald Winnicott (1896-1971). No artigo "Teatro e Infâncias: possíveis mundos de vida (e morte)" (2014) Machado relaciona a atitude de agachamento ao espaço potencial.

Se os adultos cultivarem aquele tempo-espaço necessário para o surgimento do que Winnicott (1994) definiu como espaço potencial - um lugar psíquico de troca, consolo e ilusão, entre adultos e crianças - as por assim dizer benfeitorias da ida ao teatro poderiam dar-se relacionalmente. Explico: reside no brincar, especialmente no brincar imaginativo, as sementes da teatralidade. Contar histórias para as crianças fazendo vozes; brincar junto em um teatro de fantoches; esconder-se e ser achado; desenhar figuras, recortá-las e colá-las em palitos de sorvete, para narrar uma pequena situação familiar ou extra-cotidiana... são atitudes de agachamento: maneiras de estar perto da criança mesma, compartilhando a capacidade humana da imaginação comungada em maneiras de brincar. (MACHADO, 2014, p. 08).

Estabelecer um contato com leituras teóricas que iam na contramão de uma perspectiva funcional/lucrativa de ver/pensar/fazer teatro para crianças foi fundamental para que o GETIs trouxesse à cena um material que dialogasse com uma perspectiva não reducionista, investindo em uma montagem com um repertório de ações/situações pouco tradicionais no cenário do teatro para crianças. Nosso desejo era criar situações cênicas que abrissem um espaço potencial para que jogo entre performers e audiência acontecesse, um tempo-espaço em que as crianças se sentissem convidadas à brincadeira, que elas fossem coautoras da obra.

Poder aprofundar nossa compreensão sobre o conceito de espaço potencial foi essencial para repensar o modo de nos colocarmos em cena. Para Winnicott há um campo intermediário na ação de brincar da criança que transita entre o faz-deconta e o mundo real "[...] o espaço que o brincar ocupa não fica dentro nem tampouco fora da subjetividade, fica na fronteira" (apud FRANCO, 2003, p. 02). Uma cena que se aproximasse, talvez, do devaneio, como sugere Gaston Bachelard, outro autor por nós estudado:

PEREIRA, Diego de Medeiros; NERIS, Elisabete de Paula de Lemos. Olhares sobre o teatro para crianças, as infâncias e as escolas. Revista da FUNDARTE, Montenegro, p. 105-123, ano 19, nํ 39, julho/dezembro de 2019.

Disponível em: http://.seer.fundarte.rs.gov.br/index.php/RevistadaFundarte/index> 20 de dezembro de 2019. 


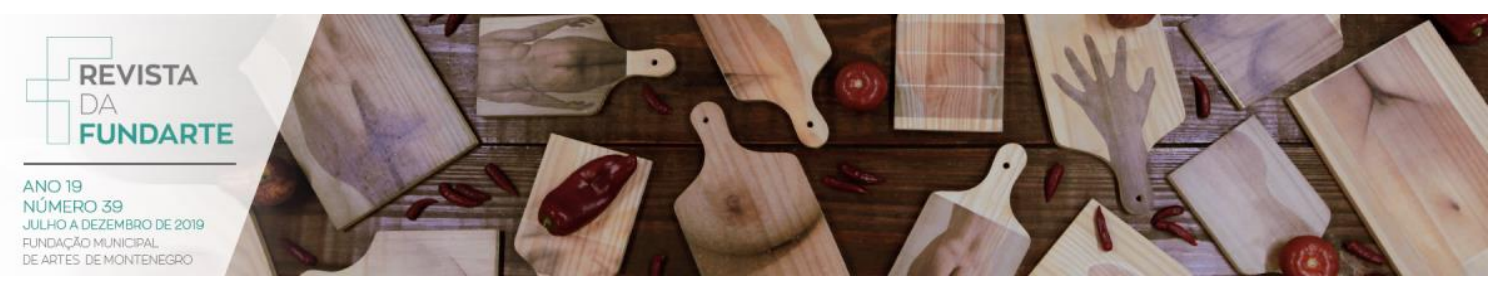

O devaneio desloca globos de pensamento sem grande preocupação de seguir o fio de uma aventura e nisso se mostra bem diferente do sonho noturno, que sempre anseia por contar-nos uma história. (BACHELARD, 1988, p. 100).

Compreender o espaço potencial como o local entre o onírico e a realidade contribuiu para que direcionássemos nosso processo de criação à experimentos que partiram de nós mesmos: nossas lembranças de infâncias, sons, músicas, objetos, histórias, passando por nossas rotinas escolares, tabus da infância, dilemas, nossas relações com as artes na escola, as brincadeiras que surgiam como fissuras no cotidiano.

Entre rotinas e devaneios de criança, o público que experimentava o espetáculo era convidado a se deixar envolver pelas memórias das infâncias das atrizes e atores que se misturam às atividades escolares e aos espaços de brincadeira que as crianças criam nas suas "fugas" do real. Instaurar um estado de jogo e mantê-lo num espaço potencial, de maneira que convocasse o público (sem ser convidado oralmente ou pelo suborno de brindes) foi um desafio no processo de criação.

Outra consideração importante de se destacar, foi o fato de termos optado por uma comunicação não completamente oralizada, manifestando por meio de nossos corpos o texto cênico, incumbindo aos movimentos o desafio de demonstrar as diversas intenções que as situações sugeriam: um sonho, o despertar, uma rotina matinal, a chamada da escola, o momento da música, o momento do teatro, a contação de histórias, a celebração de um aniversário, as brincadeiras de rua, a despedida.

Pensar em outros locais de escuta na criação voltada ao público infantil foi, também, um dos pilares da pesquisa prática. Ao experimentarem o espetáculo, as crianças podiam se colocar em qualquer lugar do espaço ${ }^{5}$, interagindo com 10 performers que ali se encontravam, realizando as situações propostas pelo roteiro.

\footnotetext{
${ }^{5}$ Em geral o espetáculo era compartilhado dentro de uma sala de aula grande, refeitório ou salão da escola, para um público médio de 60 crianças e 10 adultos.

PEREIRA, Diego de Medeiros; NERIS, Elisabete de Paula de Lemos. Olhares sobre o teatro para crianças, as infâncias e as escolas. Revista da FUNDARTE, Montenegro, p. 105-123, ano 19, no 39, julho/dezembro de 2019.

Disponível em: http://.seer.fundarte.rs.gov.br/index.php/RevistadaFundarte/index> 20 de dezembro de 2019.
} 


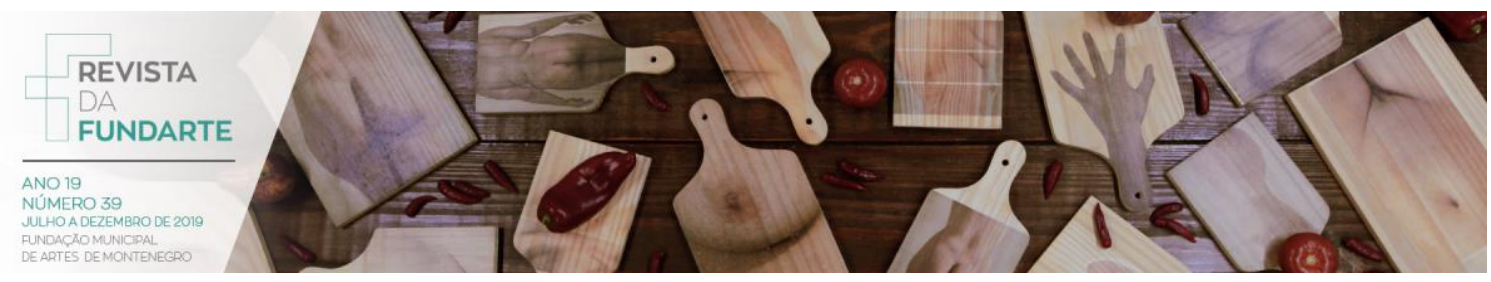

Essa abertura para que as crianças se relacionassem diretamente com 0 espaço e com os performers, permitiu que o público fosse coautor do trabalho, uma vez que suas intervenções: cantando, imitando, utilizando-se dos objetos cênicos espalhados pelo espaço, brincando ou apenas olhando para o ator ou atriz "cara a cara", alteravam as sensações e significados coletivamente construídos, a partir da proposta cênica. A redução, quase que total, de palavras possibilitou que crianças e adultos pudessem ter suas próprias leituras e percepções sobre o espetáculo.

Almejávamos despertar o interesse na participação ativa do público, embora tenhamos decidido não as convidar oralmente, mas deixando diversas brechas para essa participação, colocando-nos aptos ao improviso em cada nova apresentação. Ao analisarmos a validade do nosso posicionamento perante esse interesse, retornamos as relações que Machado (2014) estabeleceu entre espaço potencial e condutas de agachamento.

Investimos, também, na ambientação sonora como um elemento fundamental à cena. $O$ destaque mais marcante se deu na utilização do som de uma sirene escolar que delimitava os diferentes momentos do espetáculo. Sempre que ela tocava, instantaneamente, os corpos dos performers deveriam paralisar, toda a ação que estivesse em curso, deveria ser interrompida. Os performers nunca sabiam quando o sinal iria tocar; a energia presente nos corpos, manifestada por meio de brincadeiras, improvisos de histórias, pinturas livres em cartazes e criação espontânea de partituras, deveria ser contida com o sinal da escola e ceder espaço à ordem, ao silêncio, à próxima tarefa dentro da "rotina".

“Atenção para a Chamada!" circulou por 20 escolas públicas de Santa Maria cidade do interior do Rio Grande do Sul (entre instituições de Educação Infantil e Ensino Fundamental). Sua estrutura sempre causava alguns estranhamentos: as professoras nunca sabiam em quais lugares podiam sentar, uma vez que não havia essa delimitação; tentavam conter as crianças quando elas se relacionavam com as cenas, ainda que avisássemos que as crianças podiam ficar livres pelo espetáculo; muitas crianças associavam o sinal com a sirene da polícia, o que nos fazia sempre

PEREIRA, Diego de Medeiros; NERIS, Elisabete de Paula de Lemos. Olhares sobre o teatro para crianças, as infâncias e as escolas. Revista da FUNDARTE, Montenegro, p. 105-123, ano 19, nํ 39, julho/dezembro de 2019.

Disponível em: http://.seer.fundarte.rs.gov.br/index.php/RevistadaFundarte/index> 20 de dezembro de 2019. 


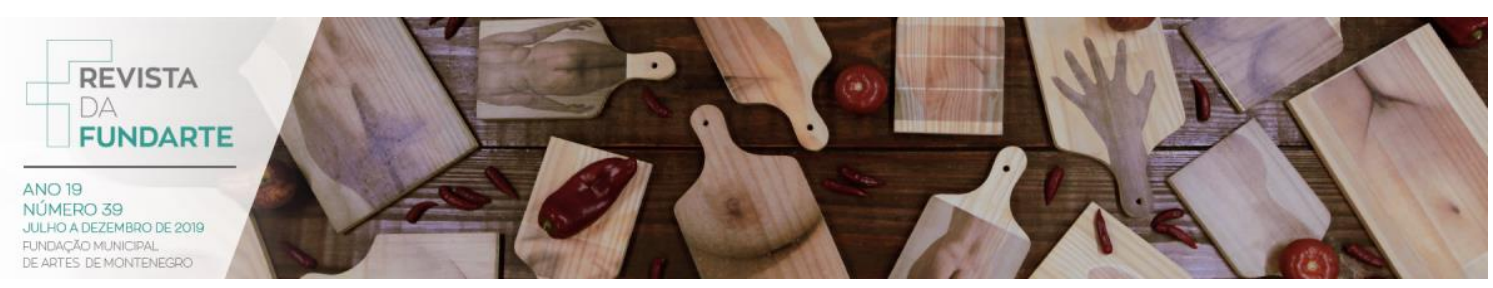

refletir sobre as semelhanças entre a repressão da escola e da polícia, entre outras questões.

Em geral, no fim dos espetáculos, as crianças tinham tomado conta de todo o espaço e os performers saiam, deixando que se evidenciasse que as crianças são as protagonistas daquele local - uma vez que estávamos no espaço da escola. Não raro as professoras nos procuravam para dizer que o espetáculo trazia muitas críticas à escola, mas que, talvez, as crianças não entendessem, enquanto os adultos, sim. Essa era, também, uma de nossas propostas: um teatro para todas as idades, em que cada público, com suas referências e repertórios, pudesse se relacionar com a cena de maneiras diferentes. Esse objetivo foi alcançado.

\section{Algumas Considerações}

Foi fundamental, a todos envolvidos na produção da montagem, mantermonos em alerta, estarmos em constante autocrítica, aprimorando, permanentemente, nosso modo de compreender as culturas infantis, na busca por nos afastarmos dos moldes tradicionais com que se tem feito teatro para crianças.

Compreender que as infâncias têm seus próprios desafios e que esses não podem ser diminuídos, tampouco simplificados pelos adultos para serem representados em cena, é entendido por nós como um ato de respeito à capacidade de leitura crítica e apreciação estética da criança.

No que tange à pesquisa teórica sobre os temas teatro e infância, o incipiente material demonstra que o teatro para crianças ainda tem um longo caminho até ser percorrido em busca de uma maior valorização, sobretudo no meio acadêmico. $O$ Grupo de Estudos sobre Teatro e Infâncias busca, ainda que em uma esfera micro, minimizar a ausência de discussões e práticas na formação de futuros professores/artistas/pesquisadores de teatro.

Percebemos que amadora ou profissionalmente, dentro ou fora da universidade, faz-se necessário que ao se trabalhar com teatro para crianças se esteja disposto a conhecer diversos procedimentos de criação no intuito de expandir

PEREIRA, Diego de Medeiros; NERIS, Elisabete de Paula de Lemos. Olhares sobre o teatro para crianças, as infâncias e as escolas. Revista da FUNDARTE, Montenegro, p. 105-123, ano 19, no 39, julho/dezembro de 2019.

Disponível em: http://.seer.fundarte.rs.gov.br/index.php/RevistadaFundarte/index> 20 de dezembro de 2019. 


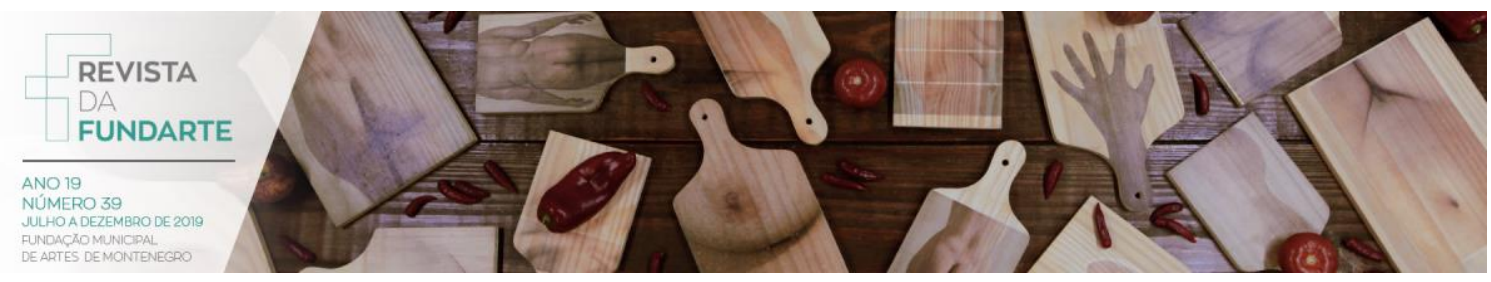

não apenas nossa prática artística, mas enriquecendo a experiência de troca com o público.

O repertório sociocultural das crianças influencia a maneira como elas lidam com os espetáculos teatrais a que assistem. Nesse sentido, parece-nos urgente que os cursos superiores de teatro se aproximem das escolas, que se coloquem em diálogo com elas e que, de fato, façam delas campos de extensão universitária e de efervescência cultural.

Em um país de tantos Pedros Bala nas praias, de Bentinhos nos seminários, Zezés a sombra de laranjeiras, Sérgios em colégios internos, Carlinhos nos engenhos, de Querôs nas Fundações Casa, de Loris Lambys, de Lorenas, Lias, Anas e Clara, assim como crianças andarilhas com vidas secas, crianças em sítios encantados, parece-nos que é o espaço potencial de jogo e o desejo de brincar que une essas diferentes infâncias (embora para algumas, esse direito seja negado). Que seja o teatro um palco para o ensaio e a criação de novas possibilidades de ser e estar criança.

\section{Referências:}

ARIÈS, Philippe. História social da criança e da família. Rio de Janeiro: Zahar, 1978.

BACHELARD, Gaston. A poética do devaneio. São Paulo: Martins Fontes, 1988.

BENJAMIN, Walter. Reflexões: a criança, o brinquedo, a educação. São Paulo: Duas Cidades, 2009.

CAMAROTTI, Marco. Dramaturgia no teatro para a infância e a juventude. Revista do $8^{\circ}$ e $9^{\circ}$ Festival Nacional de Teatro para Crianças e Jovens. Blumenau, ano 8, p. 20-22, 2005.

CARNEIRO NETO, Dib. Pecinha é a vovozinha. São Paulo: Editora Dba, 2003.

COURTNEY, Richard. Jogo, teatro \& pensamento: as bases intelectuais do teatro na educação. São Paulo: Perspectiva, 1974.

FERREIRA, Taís. A docência como arte ou a docência em arte? Questões acerca da formação de um docente-artista em teatro. Expressão, Santa Maria, v. 1, p. 95-102, 2008.

PEREIRA, Diego de Medeiros; NERIS, Elisabete de Paula de Lemos. Olhares sobre o teatro para crianças, as infâncias e as escolas. Revista da FUNDARTE, Montenegro, p. 105-123, ano 19, nํ 39, julho/dezembro de 2019.

Disponível em: http://.seer.fundarte.rs.gov.br/index.php/RevistadaFundarte/index> 20 de dezembro de 2019. 


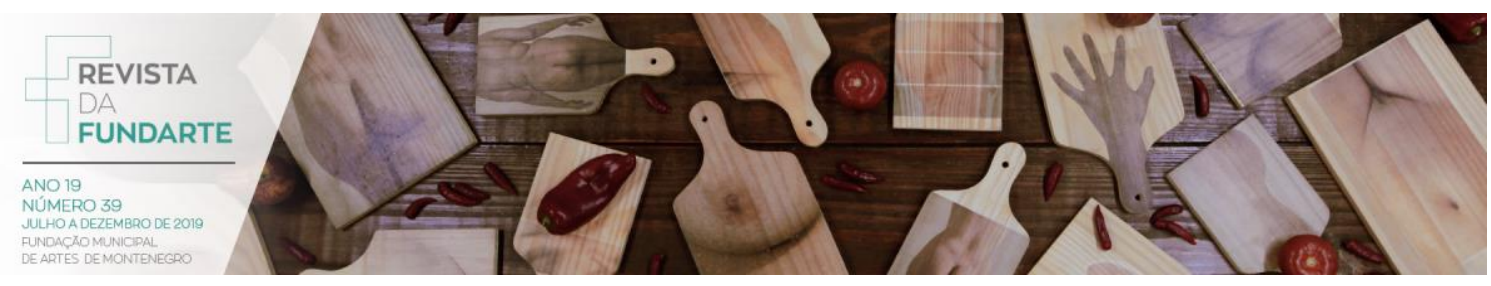

FRANCO, Sérgio de Gouvêa. O brincar e a experiência analítica. Ágora, Rio de Janeiro, v. 6, n. 1, 2003.

GIRARDELLO, Gilka. Novos tempos na produção cultural para crianças (e com elas). Revista do $8^{\circ}$ e 9o Festival Nacional de Teatro para Crianças e Jovens. Blumenau, ano 8, p. 37-39, 2005.

KOUDELA, Ingrid Dormien. Jogos teatrais. São Paulo: Perspectiva, 1984.

KÜHNER, Maria Helena. O que precisamos saber ou lembrar sobre a criança e sobre o teatro. CEPETIN, São Paulo, 2006.Disponível em:

$<$ file:///C:/Users/User/Downloads/oque precisamos saber ou lembrar\%20(2).pdf>. Acesso em: 08 jul. 2018.

LEYVA, Luvel Garcia. Em busca de uma semântica do Teatro Infantil: algumas reflexões à luz da contemporaneidade. Revista aSPAs, São Paulo, v. 2, n. 4, p. 0314, 2014.

MACHADO, Marina Marcondes. Teatro e Infância: possíveis mundos de vida (e morte). Revista aSPAs, São Paulo, v. 2, n. 4, p. 27-38, 2014.

MACHADO, Marina Marcondes. Cacos de infância: teatro de solidão compartilhada. São Paulo: FAPESP; Annablume, 2004.

PEREIRA, Diego de Medeiros. Para além dos arcos: em busca das relações entre teatro e as diferentes infâncias. Olhares e Trilhas, Uberlândia, v. 20, n. 2, p. 94-108, 2018.

PUPO, Maria Lúcia. No reino da desigualdade. São Paulo: Perspectiva, 1991.

SAINT-EXUPÉRY, Antoine de. O Pequeno Príncipe. São Paulo: Círculo do Livro, 1989.

PEREIRA, Diego de Medeiros; NERIS, Elisabete de Paula de Lemos. Olhares sobre o teatro para crianças, as infâncias e as escolas. Revista da FUNDARTE, Montenegro, p. 105-123, ano 19, no 39 , julho/dezembro de 2019.

Disponível em: http://.seer.fundarte.rs.gov.br/index.php/RevistadaFundarte/index> 20 de dezembro de 2019. 